\title{
Innate immunity and inflammation in Alzheimer's disease pathogenesis
} Imunidade inata e inflamação na patogênese da doença de Alzheimer Leonel Tadao Takada

Universidade de São Paulo, Faculdade de Medicina, Hospital das Clínicas, Departamento de Neurologia, Grupo de Neurologia Cognitiva e do Comportamento, São Paulo SP, Brasil.

Correspondence: Leonel Tadao Takada; Rua Itapeva, 538 / conj. 132; 01332-000 São Paulo SP, Brasil; E-mail:leonel.takada@hc.fm.usp.br Conflict of interest:

There is no conflict of interest to declare.

Received 18 August 2017 Accepted 25 August 2017

\section{(c) BY}

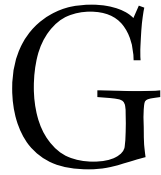

enetic studies have provided important insights into the pathogenesis of Alzheimer's disease (AD). In the early 1990s, the identification of mutations in the amyloid precursor protein $(A P P)$, presenilin1 (PSEN1) and presenilin2 (PSEN2) genes - genes that encode proteins that are involved in the amyloidogenic processing of APP - as causative of monogenic AD provided strong arguments for the amyloid cascade hypothesis ${ }^{1}$. According to the amyloid cascade hypothesis, amyloid beta (A $\left.\beta\right)$ accumulation and deposition occurs in late onset $\mathrm{AD}$ due to failure of clearance mechanisms, and is the initial event that eventually leads to neuronal and synaptic loss ${ }^{1}$.

Neuropathological findings brought up the initial clues that the innate immunity system participates in the $\mathrm{AD}$ pathogenesis, as activated microglia and astrocytes are found around neuritic $A \beta$ plaques ${ }^{1,2}$. The interest on the role of neuroinflammation grew after early epidemiological studies indicated that the use of non-steroidal anti-inflammatory drugs (NSAIDs) reduced the risk of developing $\mathrm{AD}^{3}$. Over time, studies in cell and animal models have shown that $\mathrm{A} \beta$ oligomers, protofibrils and fibrils are toxic to microglia (thus reducing their ability to promote $A \beta$ clearance) and induce the production of cytokines, and the resulting chronic inflammation promotes neurodegeneration ${ }^{2}$. Genetic association studies have reinforced the idea that microglia and chronic neuroinflammation have a more central role in the disease pathogenesis. Since the mid-2000s, genome-wide association studies (GWAS) and association studies that used whole genome or exome sequencing data, have helped identify genes that are associated with late-onset $\mathrm{AD}$; and by clustering those genes based on the analyses of biological pathways, four major pathways have been identified as implicated in the AD pathophysiology, one of which is immune response (and the others being control of endocytosis, cholesterol metabolism and ubiquitination of proteins) ${ }^{4}$. Genes such as CR1 (complement $\mathrm{C} 3 \mathrm{~b} / \mathrm{C} 4 \mathrm{~b}$ receptor 1), CD33 (CD33 molecule), and TREM2 (triggering receptor expressed on myeloid cells 2) are expressed in microglia and encode proteins that participate in the microglial response to $\mathrm{A} \beta$ deposition ${ }^{1,4,5}$. Variants in TREM2 - despite being less frequent in the population - have a similar effect size on the risk of developing $\mathrm{AD}$ to the one associated with the $\varepsilon 4$ variant of the $A P O E$ (Apolipoprotein $\mathrm{E}$ ) gene, the main genetic $\mathrm{AD}$ risk factor ${ }^{4,5}$. A more recent study that included almost 40,000 AD cases also identified $A B I 3$ (ABI family member 3 ) and PLCG2 (phospholipase $\mathrm{C}$ gamma 2), genes that are highly expressed in microglia and encode proteins that participate in the immune response ${ }^{5}$.

Inflammation is a complex and dynamic process, and during the course of $\mathrm{AD}$, it probably has protective and deleterious effects in different phases ${ }^{2,3}$. The initial accumulation of $\mathrm{A} \beta$ triggers microglia activation and $\mathrm{A} \beta$ phagocytosis, but the ongoing production of $\mathrm{A} \beta$ and release of pro-inflammatory cytokines (such as TNF $\alpha$, interleukin-1, interleukin-12, and interleukin-23) leads to a chronic inflammatory state and microglial dysfunction that hinders $\mathrm{A} \beta$ clearance $^{2}$. Anti-inflammatory cytokines, such as interleukin-10 (IL-10), have also been studied in $\mathrm{AD}$, particularly because the modulation of inflammatory processes might be a target for the disease treatment. Its exact role on the neurodegenerative processes, however, still needs more clarification; in transgenic animal studies, IL-10 has shown beneficial effects on cognition in some studies, but more recent research has indicated that IL-10 might worsen $\mathrm{A} \beta$ accumulation by inhibiting microglial phagocytosis ${ }^{6,7}$. Overall, the data currently available indicate that modulation of the inflammatory response in the early stages of the disease rather 
than an anti-inflammatory only approach might be a better treatment strategy for $\mathrm{AD}^{3,6}$. This is also supported by the results of clinical trials that used NSAIDs and failed to show clear benefits in patients with $\mathrm{AD}^{3}$.

In this context, Magalhães and colleagues ${ }^{6}$ reviewed the literature on whether single nucleotide polymorphisms (SNPs) that regulate the expression of the $I L-10$ gene affect the susceptibility to AD. Even though the findings of the sixteen studies from around the world were conflicting ${ }^{6}$ and a recent meta-analysis did not find a significant association between $-1082 \mathrm{G}>\mathrm{A}$ in $I L-10$ and $\mathrm{AD}$ risk $^{8}$, interestingly both studies conducted in Brazil showed associations between $I L-10$ polymorphisms and $\mathrm{AD}^{9}$ or cognitive impairment ${ }^{10}$.

The discrepancies across studies might be due to numerous causes, such as different sample sizes, unaccounted factors that modify $I L-10$ expression, and/or the fact that studies were performed in different populations. Indeed, most genetic association studies on $\mathrm{AD}$ have been performed in Caucasian populations, and more recently, there have been efforts to also perform those studies in populations with different racial backgrounds. These latter efforts have shown that the effect sizes of gene variants can vary significantly in different populations. Variants in the $A B C A 7$ (ATP-binding cassette sub-family A member 7) gene, for example, are associated with higher risk of $\mathrm{AD}$ among African Americans than in individuals with European ancestry $^{11}$. It is therefore important to conduct genetic association studies in the highly admixed Brazilian population, to better understand the effects of genetic variants in the risk and phenotype of $\mathrm{AD}$.

\section{References}

1. Selkoe DJ, Hardy J. The amyloid hypothesis of Alzheimer's disease at 25 years. EMBO Mol Med. 2016;8(6):1-14. https://doi.org/10.15252/emmm.201606210

2. Heppner FL, Ransohoff RM, Becher B. Immune attack: the role of inflammation in Alzheimer disease. Nat Rev Neurosci. 2015;16(6):358-72. https://doi.org/10.1038/nrn3880

3. Heneka MT, Carson MJ, El Khoury Jl, Landreth GE, Brosseron F, Feinstein DL et al. Neuroinflammation in Alzheimer's disease. Lancet Neurol. 2015;14(4):388-405. https://doi.org/10.1016/S1474-4422(15)70016-5

4. Jones L, Lambert JC, Wang LS, Choi SH, Harold D, Vedernikov A et al. Convergent genetic and expression data implicate immunity in Alzheimer's disease. Alzheimers' Dement. 2015;11(6):658-71. https://doi.org/10.1016/j.jalz.2014.05.1757

5. Sims R, van der Lee SJ, Naj AC, Bellenguez C, Badarinarayan N, Jakobsdottir $\mathrm{J}$ et al. Rare coding variants in PLCG2, ABI3, and TREM2 implicate microglial-mediated innate immunity in Alzheimer's disease. Nat Genet. 2017;49(9):137384. https://doi.org/10.1038/ng.3916

6. Magalhães CA, Carvalho G, Sousa LP De, Caramelli P, Gomes KB. Alzheimer's disease and cytokine IL-10 gene polymorphisms : is there an association ? Arq Neuropsychiatr. 2017;75(9):649-56. https://doi.org/10.1590/0004-282X20170110
7. Michaud JP, Rivest S. Anti-inflammatory signaling in microglia exacerbates Alzheimer's disease-related pathology. Neuron. 2015;85(3):450-2. https://doi.org/10.1016/j.neuron.2015.01.021

8. Mun MJ, Kim JH, Choi JY, Jang WC. Genetic polymorphisms of interleukin genes and the risk of Alzheimer's disease: an update meta-analysis. Meta Gene. 2016;85(3):450-2. https://doi.org/10.1016/j.mgene.2016.01.001

9. Moraes CF, Benedet AL, Souza VC, Lins TC, Camargos EF, Naves JOS et al. Cytokine gene polymorphisms and Alzheimer's disease in Brazil. Neuroimmunomodulation. 2013;20(5):239-46. https://doi.org/10.1159/000350368

10. Fraga VG, Guimarães HC, Teixeira AL, Barbosa MT, Carvalho MG, Caramelli $P$ et al. Polymorphisms in cytokine genes influence cognitive and functional performance in a population aged 75 years and above. Int J Geriatr Psychiatry. Forthcoming 2016. https://doi.org/10.1002/gps.4627

11. Reitz C, Jun G, Naj A, Rajbhandary R, Vardarajan BN, Wang $L$ et al. Variants in the ATP-binding cassette transporter (ABCA7), apolipoprotein E $\varepsilon 4$, and the risk of late-onset Alzheimer disease in African Americans. JAMA. 2013;309(14):1483-92. https://doi.org/10.1001/jama.2013.2973. 